\title{
Arabic Language Learning Program in the Language Tourism Village in برنامج تعليم اللغة العربية بقرية السياحة اللغوية في /Terms of Learning Management ضوء الإدارة التعليمية
}

Nuning Putri Wulandari

MTs Al Fidaus, Matesih

nuningfitri841@gmail.com

\begin{abstract}
The Language Tourism Village Program in Pakel is a program that teaches Arabic which requires management in the teaching process. The purpose of this study was to determine and describe the implementation of the Arabic language program in the Arabic tourism village in Pakel village, Karangpandan, Karanganyar. The results of this study indicate: 1) in planning, the purpose of learning Arabic in the Language Tourism Village in Pakel uses the curriculum applied in the Language Tourism Village at the Ali Royah Sukabumi Islamic Boarding School which has been designed completely by the curriculum developed by the Arabic book author Baina yadaik; 2) All teachers in this program are graduates of the Ali Rayah Sukabumi Islamic boarding school; 3) Implementation, consisting of 3 activities, namely: initial activities, core activities and final activities. 4) Evaluation, held every two weeks.
\end{abstract}

Keywords : Management, teaching Arabic, language tourism villages.

\begin{abstract}
ABSTRAK
Program Desa wisata Bahasa di Pakel merupakan sebuah program yang mengajarkan Bahasa Arab yang membutuhkan pengelolaan dalam proses pengajarannya. Tujuan penelitian ini adalah untuk mengetahui dan mendeskripsikan penyelenggaraan program bahasa Arab di desa wisata Bahasa Arab di desa Pakel, Karangpandan, Karanganyar. Hasil penelitian ini menunjukkan: 1) didalam perencanaan, tujuan pembelajaran bahasa Arab di Desa Wisata Bahasa di Pakel menggunakan kurikulum yang diterapkan di Desa Wisata Bahasa di Pondok Pesantren Ali Royah Sukabumi yang telah dirancang secara lengkap sesuai dengan kurikulum yang dikembangkan oleh penulis buku bahasa arab Baina yadaik; 2) Semua pengajar pada program ini merupakan lulusan dari pondok pesantren Ali Rayah Sukabumi; 3) Pelaksanaan, terdiri dari 3 kegiatan yaitu: kegiatan awal, kegiatan inti dan kegiatan akhir. 4) Evaluasi, dilaksanakan dua minggu sekali.
\end{abstract}

Kata Kunci : pengelolaan, pengajaran bahasa arab, desa wisata bahasa. 
قسم نظام التعليم الوطني المسارات التعليمية إلى الثلاثة هي التعليم الرسمي وغير الرسمي والتعليم

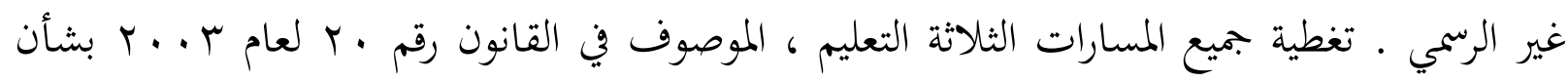
النظام التعليم الوطني التعليم النظامي هو مسار تعليمي منظم ومستوى يتكون من التعليم الأساسي والثانوي والتعليم العالي التعليم غير الرسمي هو مسارات تعليمية خارج التعليم التي يمكن تنفيأها بطريقة منظمة و المستويات والتعليم غير الرميمي هو مسار التربية الأسرية و البيئة. هناك عدة أسباب وراء تقسيم نظام التعليم الثلاثة يكمل كل منهما الآخر ـ التعليم غير الرميمي وني

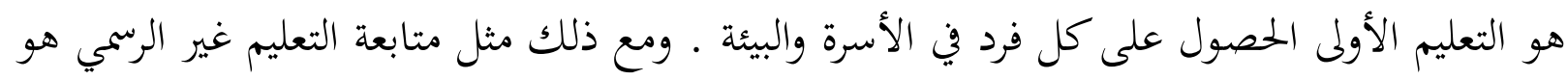
التعليم الرسمي ـ لكن ، لعدم تمبادرة التعليم الري اللوصول إلى جميع الطبقات حتى التى التعليم غير رسمية

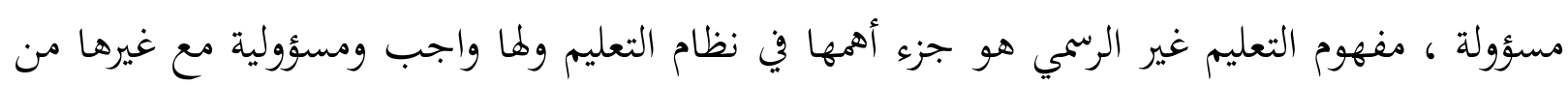
التعليم.

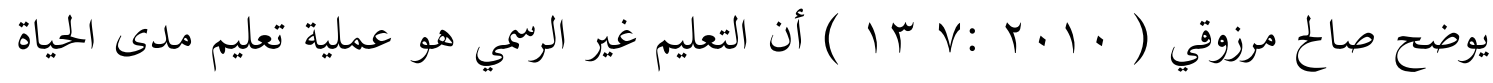

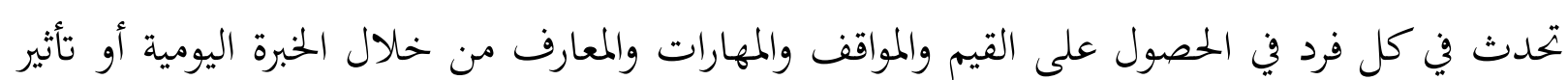

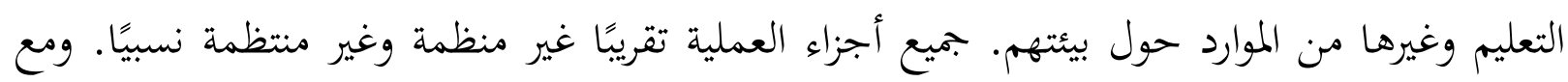
ذلك ، هذا لا يعني أن تكون غير مهم في عملية تشكيل الشخصية. مفهوم التعليم غير الرسمي هو مفهوم التعليم والتعلم الذي يعتمد على المجتمع · على أمل تغيير

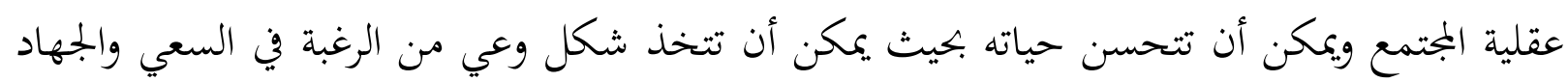
من أجلها تغيير قدراقم من خلال العمليات التعليمية غير الرسمية يمكن تمكينهم قانون التعليم الوطني

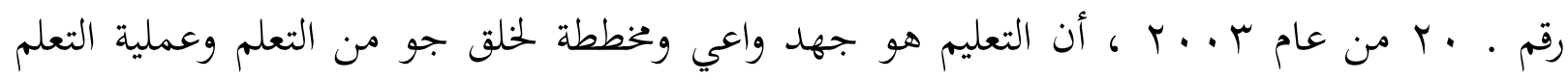

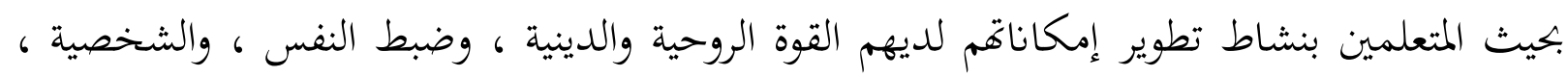

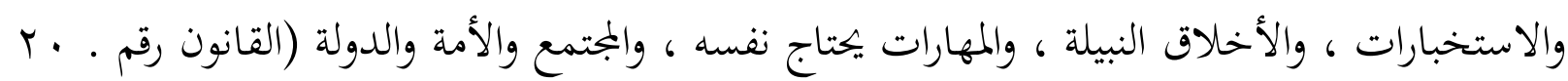

حين أن التعليم غير الرسمي هو عملية تعليم يتم تنظيمها خارج النظام المدرسي أو التعليم الرسمي، يتم تنفيذها بشكل منفصل أو هو جزء مهم من نشاط أكبر يهدف إلى خدمة أهدين أهداف معينة

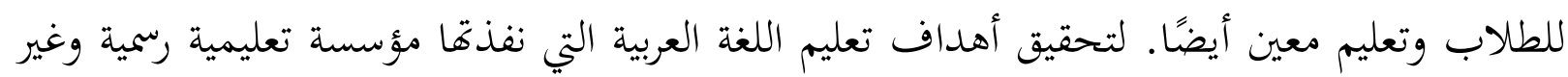


رسمية بما في ذلك قرية السياحة اللغوية ، من الطبيعي أن تكون هناك حاجة إلى إدارة جيدة لتعلم اللغة العربية وفقًا لمعنى الإدارة نفسها والتي تشمل: التعلم تخطيط وتنظيم التعلم وتنفيذ التعلم وتقييم التعلم ،

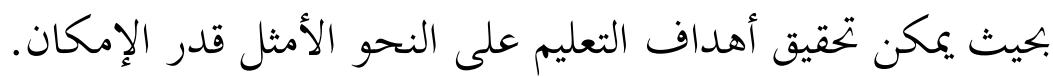

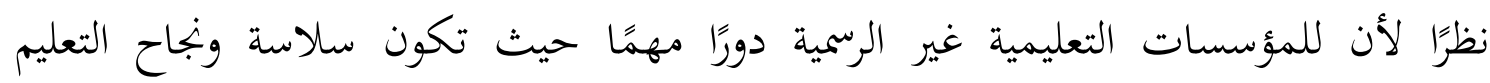
مسؤولية. في هذه الحالة هناك حاجة إلى إدارة ويجب أن تكون مملوكة من قبل كل مؤسسة تعليمية.

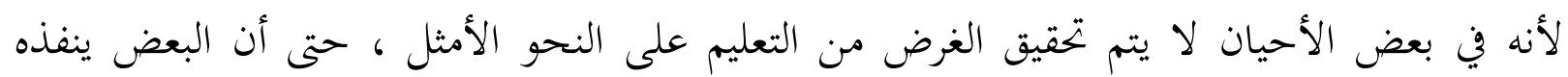

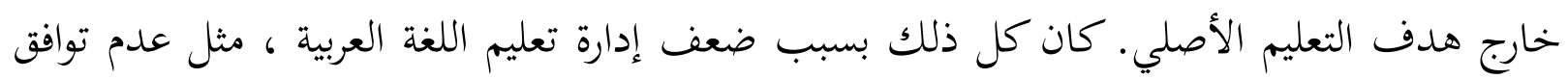
المواد مع الطريقة المطبقة.

قرية السياحة اللغوية فاكيل هي إحدى القرية التي تولي اهتمامًا لأهمية اللغة العربية كما يتضح من وجود العديد من برامج تعليم اللغة العربية هناك. التعليم في مجتمع فاكيل هو تعليم غير رسمي. في هذه الحالة قرية السياحة اللغوية فاكيل تنقسم إلى عدة فئات وهي صباح العربي، اللغة العربية لتحديد المعلم، اللغة العربية للأمهات، اللغة العربية للأطفال، وتعليم العربية للجمهور.

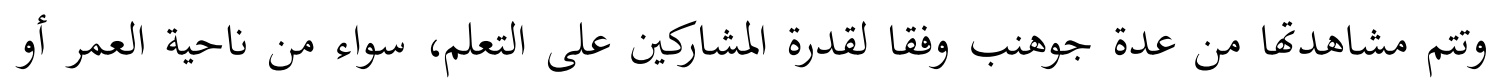

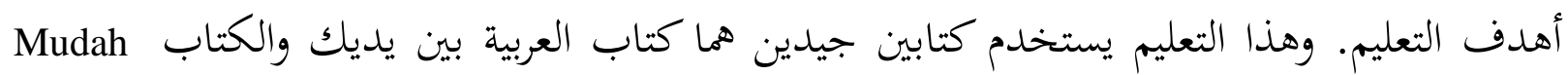
Bahasa Arab SD/MI المجتمع الناطق بالعبية وتحسين مستويات معيشتهم في المستقبل. بالإضافة إلى تمكين بجتمع فاكيل بشكل مستقل و قادر على تطوير قرية السياحة اللغيية. يجب إجراء هذا البحث لأن إدارة برامج تعليم اللغة العربية المنفذة في قرية السياحة اللغوية هي برنامج جديد لم يتم تنفيذه في المؤسسات ، خاصة في القرى الأخرى. بحيث يمكن للباحثين من خلال هذا البحث معرفة المزيد حول إدارة برامج تعليم اللغة العربية المنفذة في قرية السياحة اللغوية. بالإضافة إلى ذلك ، يمكن استخدام هذا البحث كمواد مرجعية ليتم تطبيقها في المؤسسات التعليمية غير الرسمية

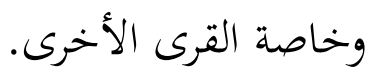
من سياق البحث أعلاه ، يهتم الكاتب بالدراسة بشكل أعمق عملية إدارة برنامج تعليم اللغة العربية في قرية سياحة اللغاوية تحت عنوان البحث "برنامج تعليم اللغة العربية بقرية السياحة اللغوية فكيل كارانج فاندان كارانج أنيار في ضوء الإدارة التعليمية، . 


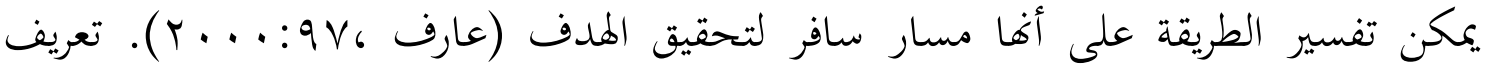
طريقة البحث هو استراتيجية عامة تم اعتمادها لجمع وتحليل البيانات اللازمة لمعالجة المشكالات التي

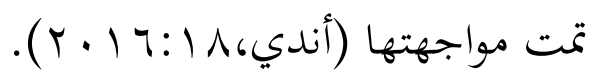

استخدم هذا البحث طريقة نوعية مع فج وصفي. يعرّف Creswell البحث النوعي بأنه عملية من الاستقصاء والفهم على أساس تقليد الاستكشاف الاستقصائي في الكائن الذي تتم دراسته من خلال تحليل السلوك والكلمات ووجهات نظر المخبر (Emzir، ا:r( •r). ورأى سوغيونو أيضًا البحث النوعي على أنه دراسة وصفية أكثر من خلال تحليل الكائنات قيد الدراسة التي تنشأ من جمع البيانات في شكل كلمات أو صور ولا تركز على الأرقام (Sugiyono, 18:2016). الغرض من البحث النوعي هو العثور على إجابات للأسئلة التي تمت مناقشتها من خلال معلومات حول الظواهر الرئيسية التي تم

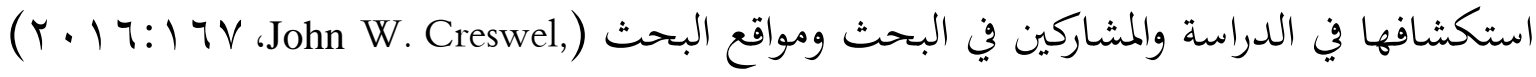
إجراء هذا البحث في قرية السياحة اللغوية فاكيل كارانج فاندان كارانج أنيار جاوة الوسطى

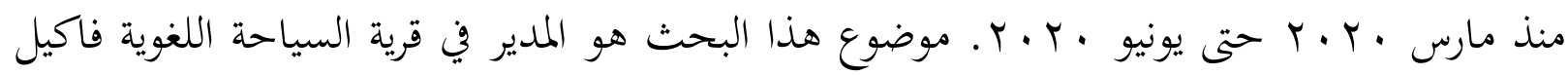
كارانج فاندان كارانج أنيار و المخبر المؤسسون والمعلمون والطلاب والسكان المحلين وقادة المجتمع في قرية السياحة اللغوية فاكيل كارانج فاندان كارانج أنيار. في اخذ البيانات لهذا البحث تستعمل المالاحظة والمقابلة والتوثيق. فالمالاحظة الملاحظة هي تقنية لجمع البيانات يتم إجراؤها من خلال الباحثة الذين يتدخّلون في الجمال مباشرة في مراقبة الأمور المتعلقة بشيء ما سيتم فحصه (حميد فتليما، باج: 1 1 ـ ( ). يتم استخدام هذه الطريقة لملاحظة مباشرة كيفية عملية الحوكمة برنامج تعليم اللغة العربية بقرية السياحة اللغوية فاكيل كارانج فاندان كارانج أنيار. والمقابلة هي تقنية لجمع البيانات يتم إجراؤها عن طريق طرح أسئلة معينة على المخبرين أو المخبرين

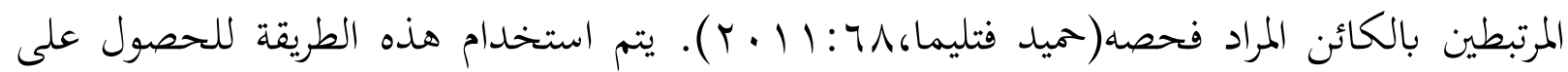
البيانات مباشرة من الموضوعات البحثية في شكل معلومات تتعلق بعملية الحوكمة برنامج تعليم اللغة العربية بقرية السياحة اللغوية فاكيل كارانج فاندان كارانج أنيار. والتوثيق هو تقنية لجمع البيانات من خلال وثائق مهمة مثل المالاحظات والكتب وتقارير العمل ، المذكرات وأرشيفات المدرسة وما إلى ذلك 


\section{ATHLA : Journal of Arabic Teaching, Linguistic And Literature, 1, (2), 2020}

تدعم بيانات البحث(Emzir 62: 2012) يعرّف سوغيونو التوثيق بأنه عملية جمع البيانات من قبل

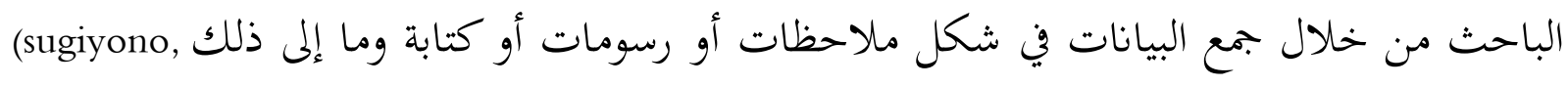
(82:2012 تستخدم هذه الطريقة لتعزيز الحصول على البيانات من الملاحظات والمقابلات.

وبعد أن تجمع البيانات فتحلل بطريقة التثليث. التثليث هو أسلوب يستخدم لاختبار موثوقية

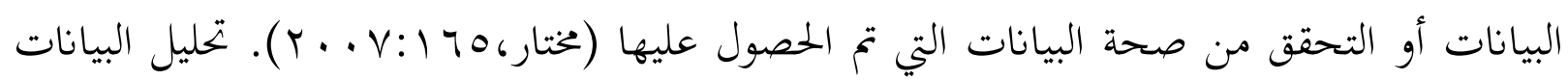

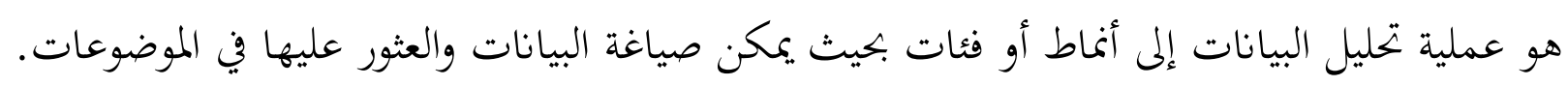

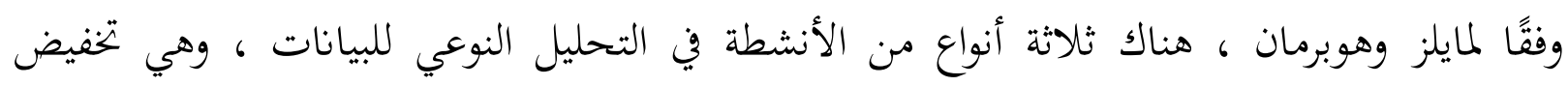

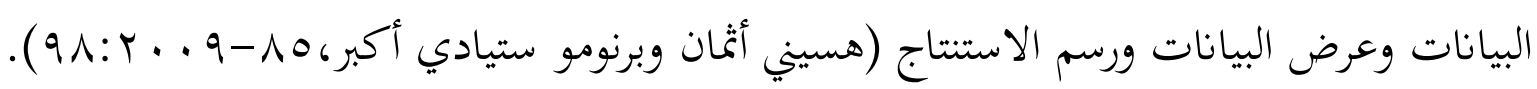

\section{نتائج البحث}

\section{إدارة تعليم اللغة العربية}

في الاستخدام الحديث العام ، تُعرّف الإدارة بأها العملية التي تُوِّهه بها المجموعة إجراءاقا لتحقيق هدف مشترك. يُنظر إلى مصطلح الإدارة كعملية اجتماعية مصممة لضمان تعاون ومشاركة

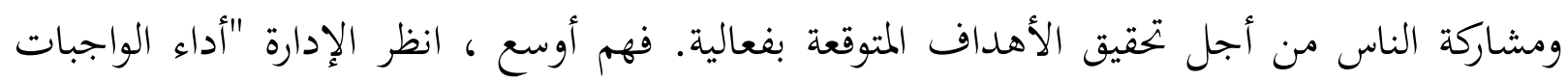

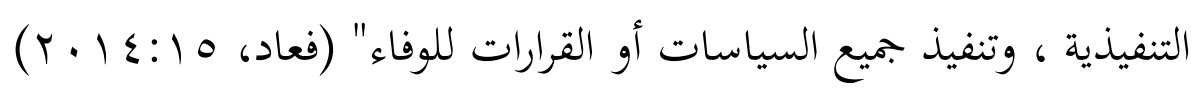

في الأساس ، الإدارة هي نشاط أو نشاط بتحاري يرتبط بإدارة الموارد البشرية والموارد التنظيمية

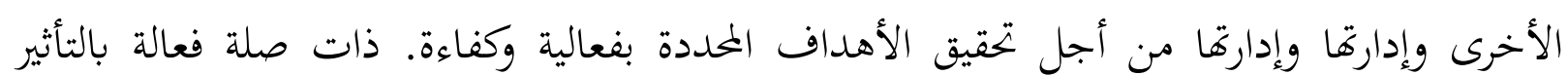
الناتج عن النشاط التجاري. بينما تتسم الكفاءة بأها مقياس لمستوى استخدام أدوات الإدارة المختلفة (القليلة ، الرخيصة ، السريعة) مثل المال والموارد البشرية والسلع وأدوات الإدارة الأخرى. (أمين

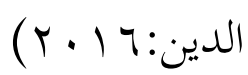

الإدارة هي في الأساس عملية استخدام الموارد بفعالية لتحقيق أهداف أو أهداف معينة. يُعرف

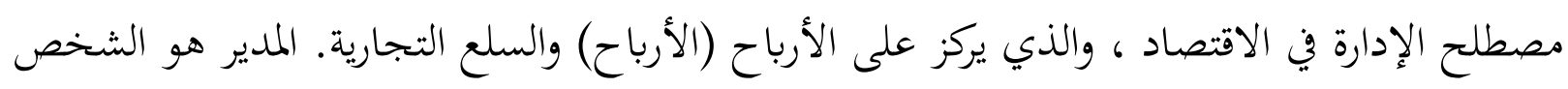
الذي يستخدم سلطة وحكمة المنظمة / الشركة لنقل موظفيه أو مرؤوسيه لتحقيق الأهداف المحددة.

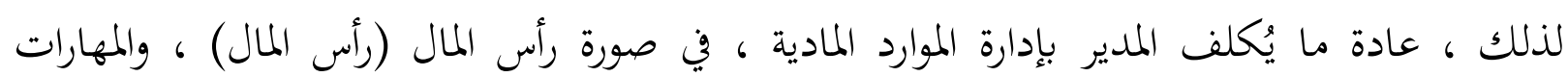


البشرية (المهارات البشرية) ، والمواد الصفية (المواد الخام) ، والتكنولوجيا ، من أجل توليد الإنتاجية

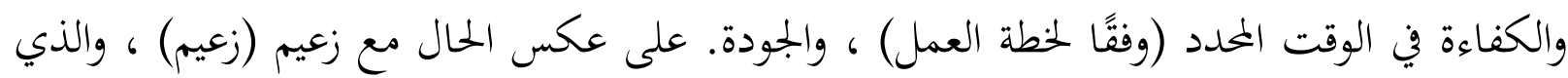

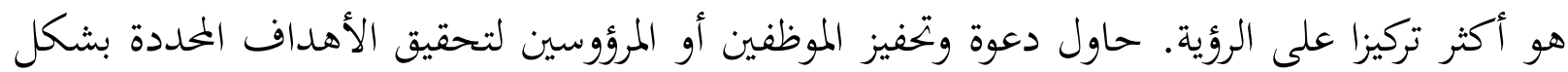

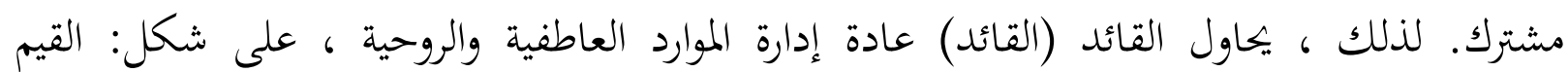

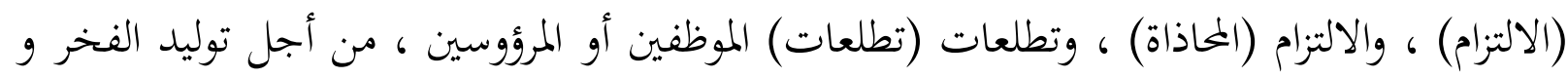

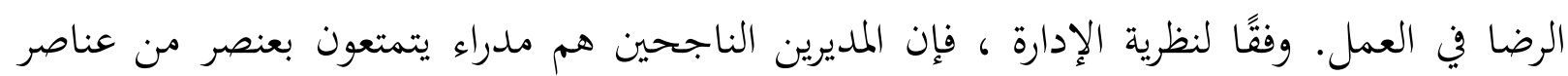
القيادة (القيادة) ويمكنهم تطبيقه وتطويره. بمعنى آخر ، المديرون القادرون على العمل كقادة (المدير

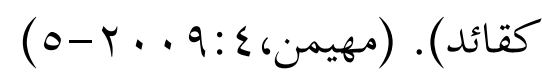

الإدارة مرادفة للأنشطة المتعلقة بإدارة أو التعامل مع شيء لصالح نجاح الهدف المنشود. وبالتالي

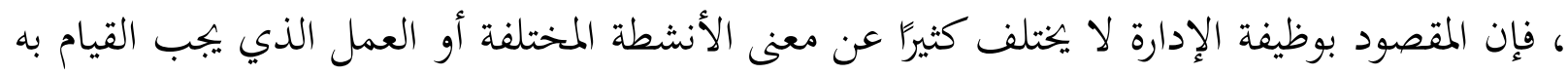

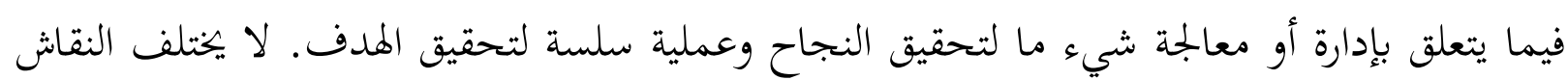

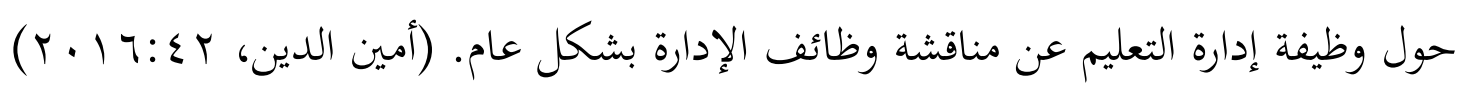
من وجهات النظر العديدة المذكورة أعلاه والتي غالباً ما تستخدم وسهلة التنفيذ هي وجهات G.R.Terry, النظر التي أعرب عنها وجها تخطيط التخطيط أو ما يقال في الإنجليزيةب planning عبارة عن أسلوب أو منهج حديث يهدف إلى

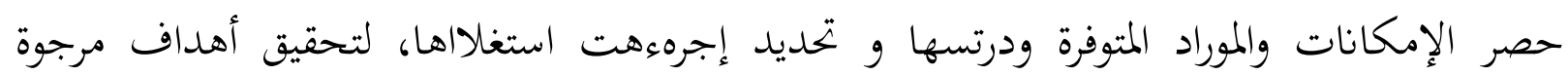

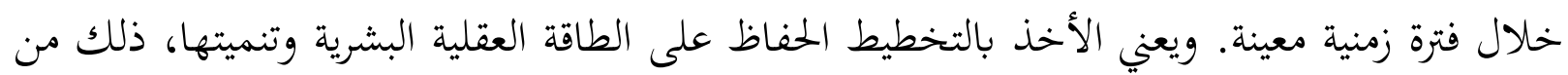
خلال استخدامها في حل المشكلات حلا أمثال، عن طريق الأسلوب العلمي في التفكير، ويعمل التخطيط عادة على دراسة الموارد أو المصادر الطبيعية ومصادر الإنتاج، بقصد المواءمة بينها و بين

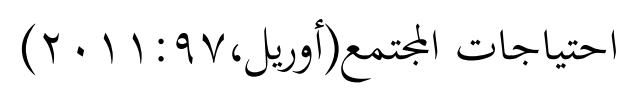

إن الغرض من هدف التعليم الإداري في هذا الوصف هو جميع أنواع الأنشطة الإدارية التي تشارك بشكل مباشر أو غير مباشر في أنشطة التعليم. كنقطة مركزية هي نشاط التعليم في المدارس. 
ATHLA : Journal of Arabic Teaching, Linguistic And Literature, 1, (2), 2020

ومع ذلك ، نظرًا لأن الأنشطة في المدرسة لا يمكن فصلها عن خطوط الدوائر الرسمية وغير الرسمية ، بالطبع تتم مناقشة نطاق نظام التعليم أيضًا على المستوى المركزي.

إذا فهمنا مرة أخرى معنى إدارة التعليم ، أي وجود جهود مشتركة لتحقيق الأهداف المحددة ،

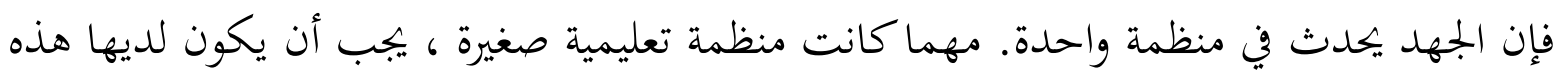

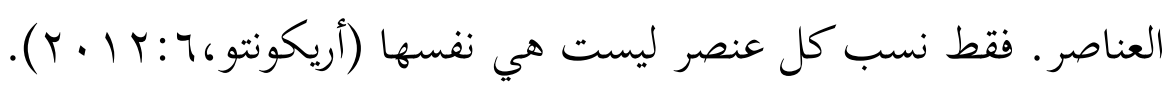

( ) تنظيم

التنظيم هو عملية هيكلة الهيكل التنظيمي وفقًا لأهداف المنظمة ومواردها والبيئة المحيطة بها.

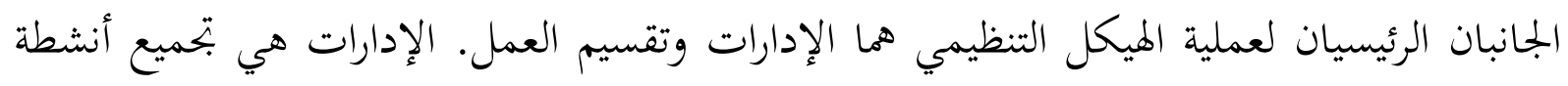

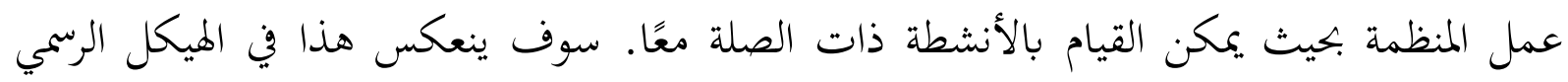

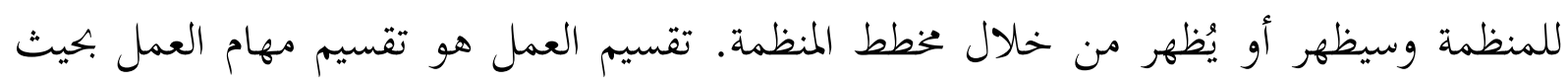

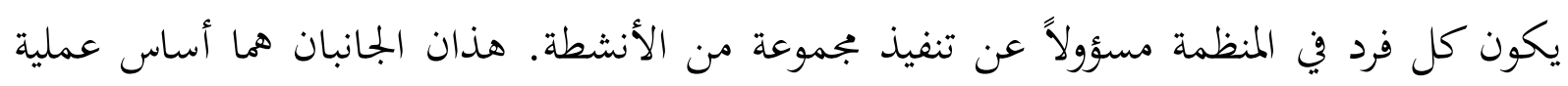

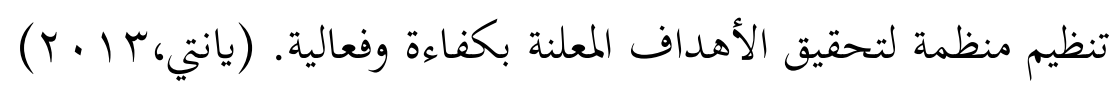

(r

التنفيذ هو إحدى وظائف الإدارة المرتبطة بالجهود المبذولة لتحقيق أول وظيفة إدارية ، وهي

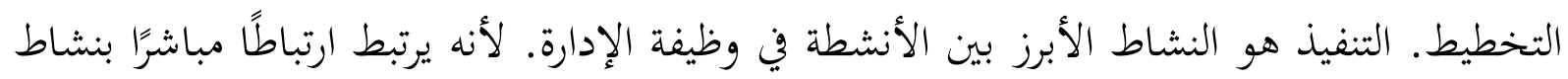
تققيق شيء لم يتحقق بعد (التخطيط) ، ووضع خطط في شكل إجراءات ملموسة من خلال تعبئة

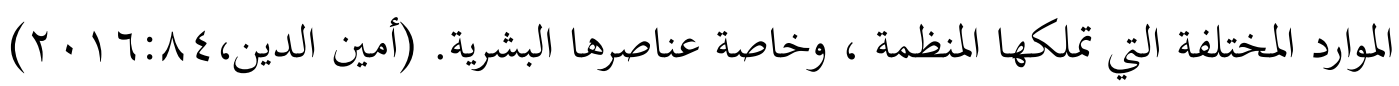

التنفيذ أو التشغيل هو جهد يبذل لتحقيق الأهداف وفقًا لخطة محددة مسبقًا حتى لا تحيد أو تخرج عما حددته المنظمة. يعني تحفيز ذلك تنفيذ الأشخاص أو نقلهم ليريدوا العمل بمفردهم أو بوعي

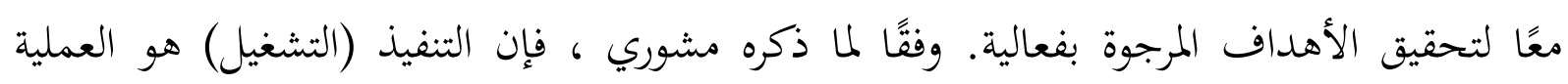
برمتها في تشجيع العمل على المرؤوسين حتى يرغبون في العمل بإخلاص من أجل تحقيق الأهداف

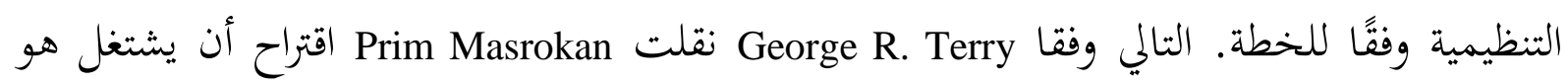


محاولة لنقل أعضاء المجموعة بطريقة يرغبون فيها ويحاولون تحقيق أهداف المنظمة وأهداف أعضاء

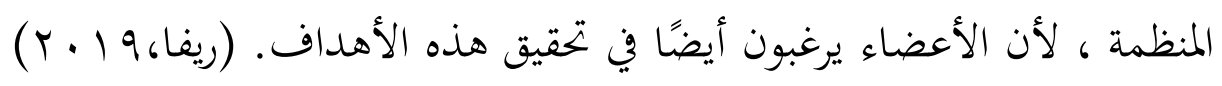
يتم التعبئة في عملية التعلم من قبل المعلمين مع جو تعليمي بحيث يمكن للطلاب القيام

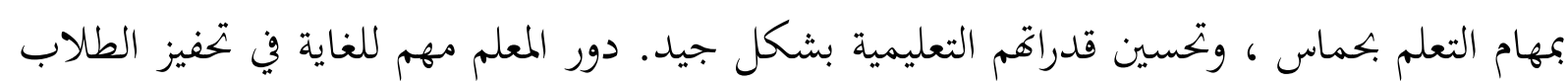
وتحفيزهم على القيام بأنشطة تعليمية سواء في الفصل أو في المختبر أو في المكتبة أو في أماكن أخرى

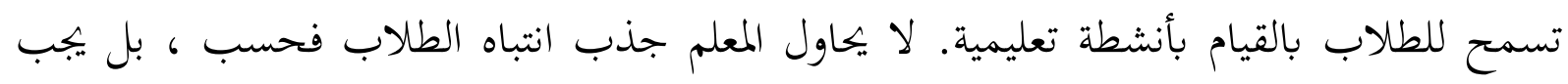
على المعلم أيضًا زيادة أنشطة طلابه من خلال الأساليب وطرق التعلم المناسبة لمواد التعلم التي يقدمها بالئه

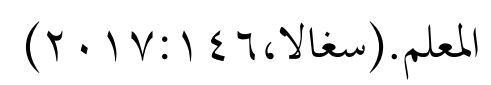

الإشراف هو جهد القائد لمعرفة جميع الأمور المتعلقة بتنفيذ العمل ، وخاصة لمعرفة العمل

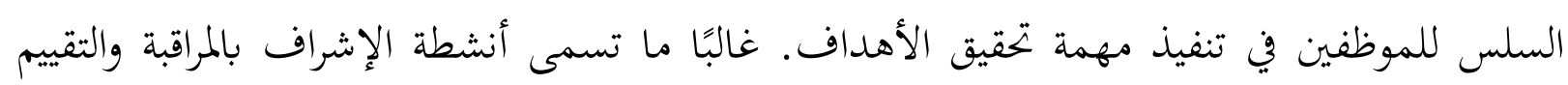

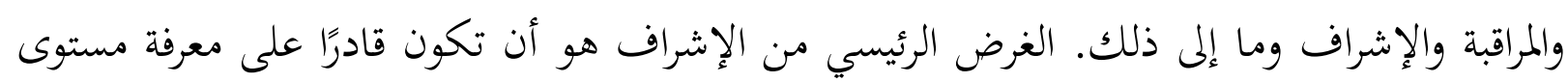

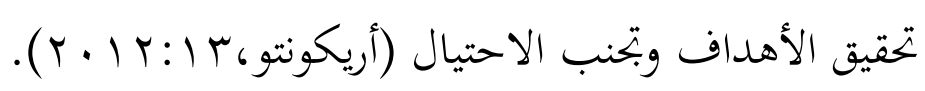

الإشراف أو السيطرة هو نشاط يتم القيام به للإشراف على وقياس ومقارنة الأنشطة التي تم

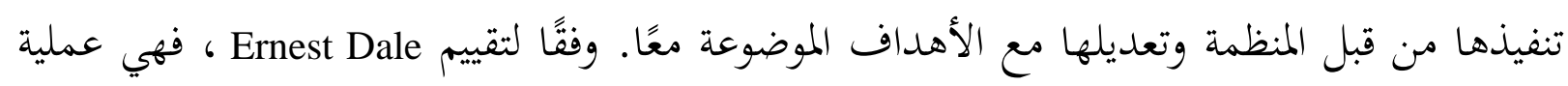

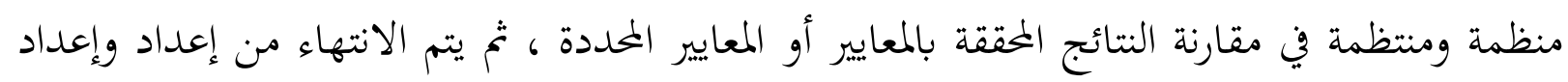

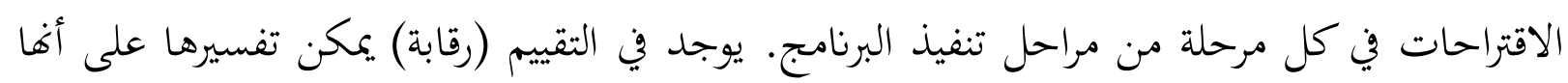

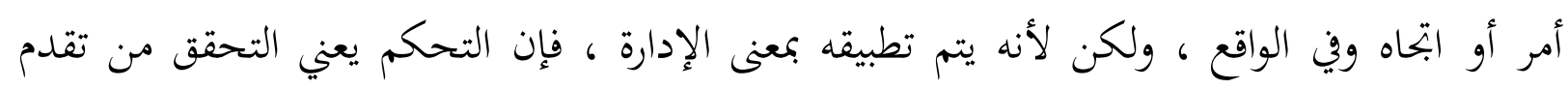

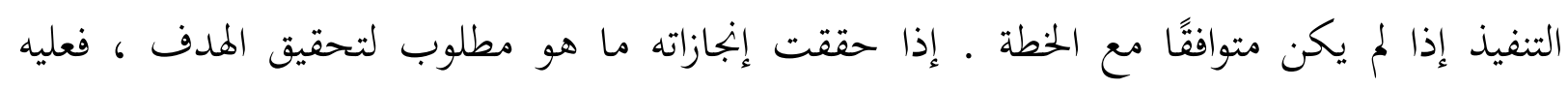

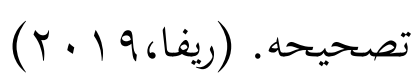

الإشراف (السيطرة) كجزء من وظيفة الإدارة الأخيرة ، لديه العديد من الوظائف في تحقيق

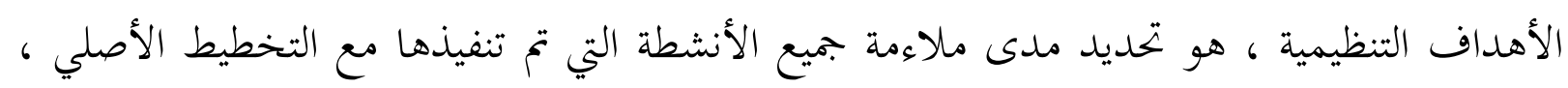

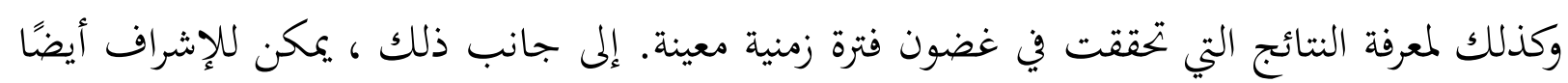


ATHLA : Journal of Arabic Teaching, Linguistic And Literature, 1, (2), 2020

اكتشاف سوء سلوك الأعضاء بحيث لا يمكن إيجاد حل. وتتمثل الوظيفة الأخرى في تحديد البيانات

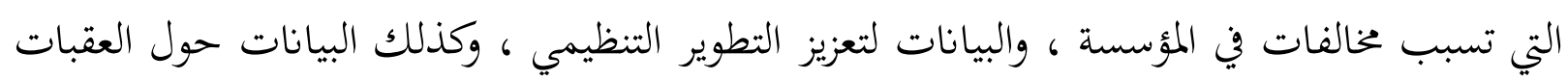
التي يواجهها جميع الأعضاء.

بالإضافة إلى ذلك ، فإن وظيفة الأنشطة الإشرافية تعرف أيضًا مدى تحقيق الأهداف

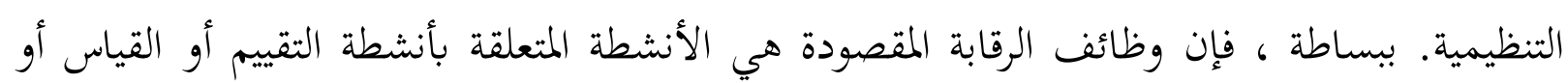

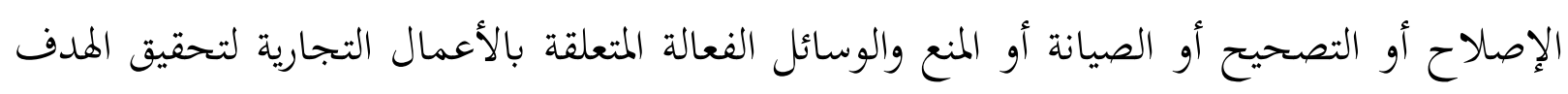

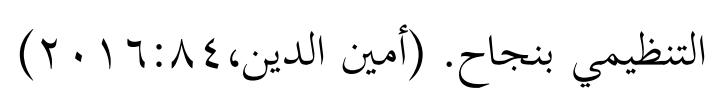

الصورة العامة عن قرية السياحة اللغوية فاكيل

تقع قرية السياحة اللغوية في الحي فاكيل منطقة كارانج فاندان بكارانج أنيار جاوى الوسطى إندونيسييا. وكان موقع قرية السياحة اللغوية قريبا من معهد عش كريما. قرية فاكيل نفسها هي المتقابلة

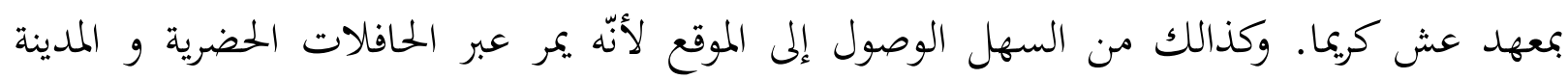
تاوانج مانجو . تنتشر قرية السياحة اللغوية في قرية صغيرة، هناك عدة نقاط كمكان لتعليم اللغة العربية

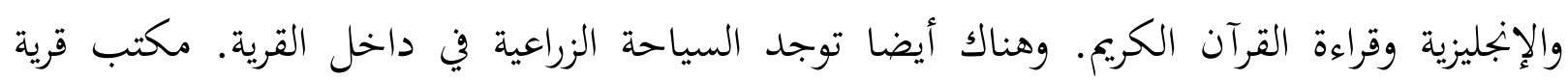

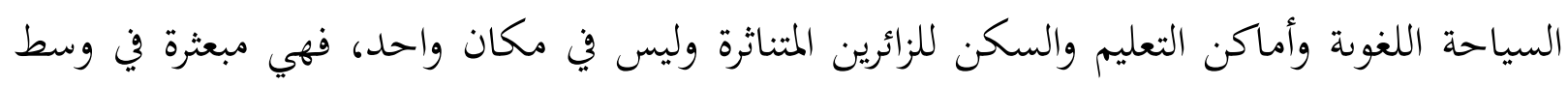

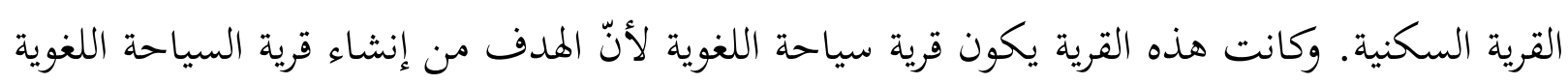

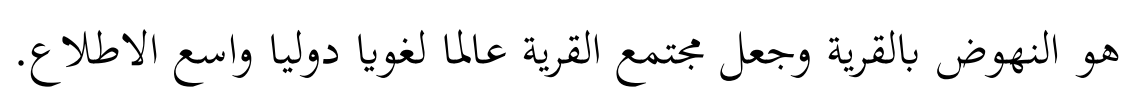

قد أنشئت قرية سياحة اللغوية في السنة V V P م بالتفكير العميق لرئيس المؤسسة والأساتذ

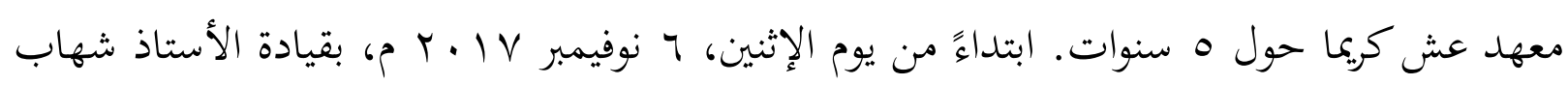

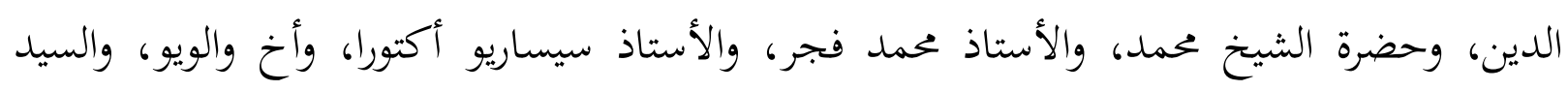

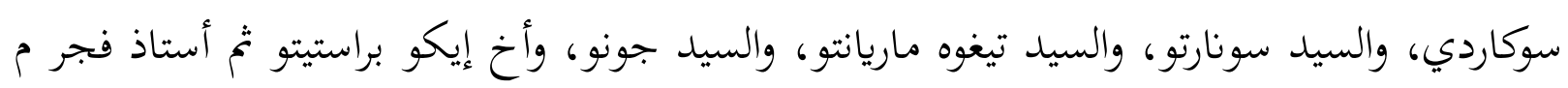
وأخ نور هداية و بر والدين ثم اخترع المفهوم قرية اللغة.

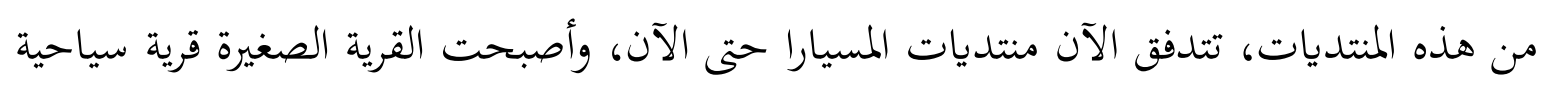

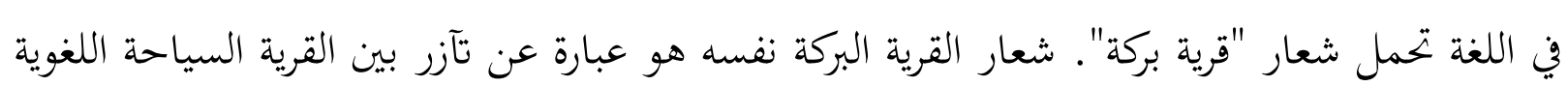


ووكالات الزكاة الوطنية كارانج أنيار التي ولدت اتفاقية مع دخول برامج وكالات الزكاة الوطنية إلى قرية سياحة اللغة لإصلاح مجتمع كارانج أنيار بشكل عام و مقيمي فاكيل بشكل خاص. وأما خلفية إنشاء قرية السياحية اللغوية هي:

أ) الحاجة إلى نظام تعلّم تعليمي غير رسمي قائم على المجتمع لا يقتصر على العدد والوقت والمكان

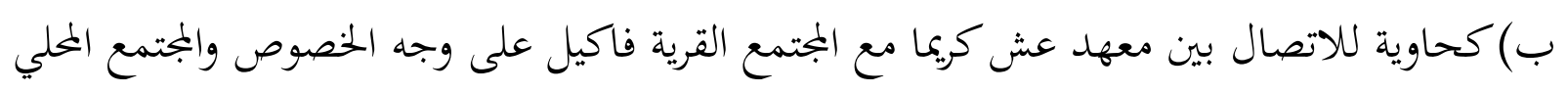

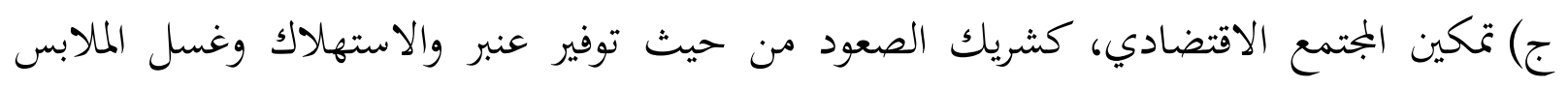
وغيرها.

د) يجب أن يكون مكانا للطلاب في مجال العمل الميداني / التفاني الذي هو أكثر كثافة في الدعوة

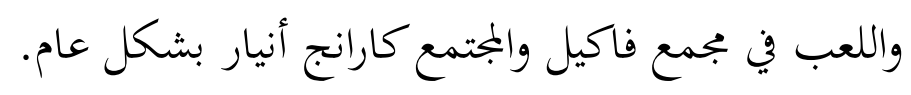

برامج التعليم اللغة العربية بقرية سياحة اللغة العربية بفاكيل

برنامج التعليم هو مجموعة من الخطط والترتيبات المتعلقة بالأهداف والمحتوى ومواد التعلم وكذلك الطرق المستخدمة كمبادئ توجيهية لتنظيم أنشطة التعلم لتحقيق الأهداف التعليمية ، وفي هذه التهني

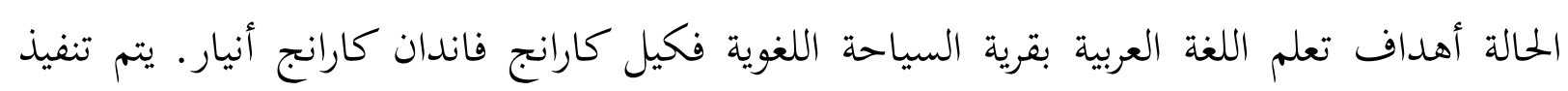
المنهج بقرية السياحة اللغوية فكيل كارانج فاندان كارانج أنيار يستخدم أو يعتمد من معهد علي الرّاية

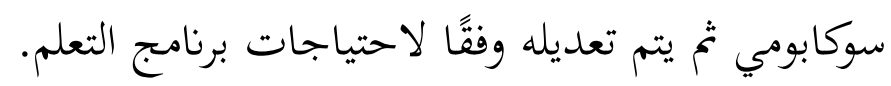

من خلال أنشطة الملاحظة عبر الإنترنت، ترى الباحثة أغها من الصحيح أن الكتاب يستخدم

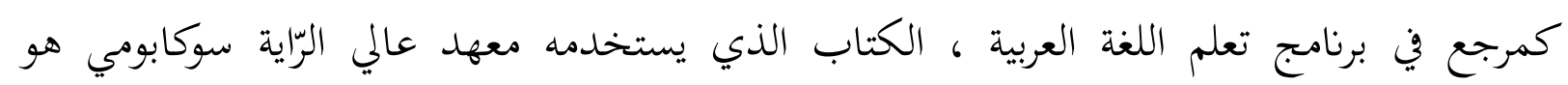

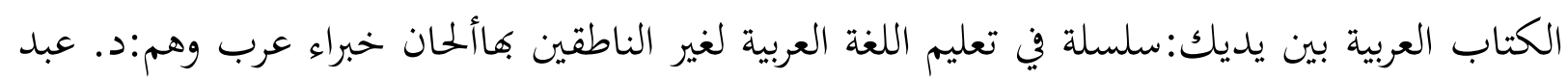

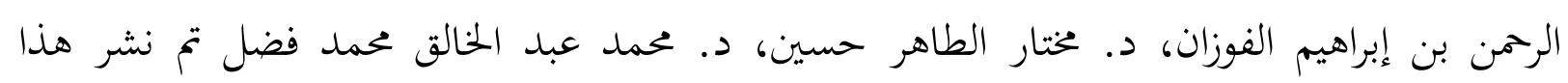

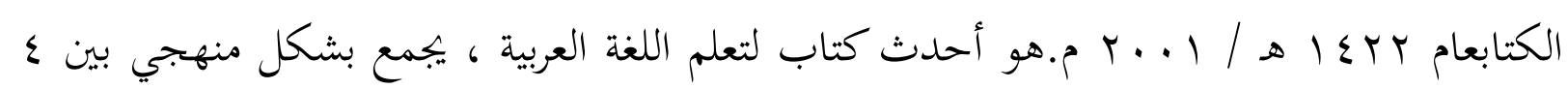

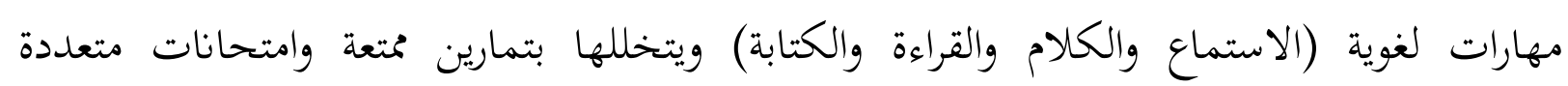
المستويات مما يسهل على أي شخص مَنْ يتعلمه. 
بناء على البيانات التي تمّت لحصول عليها من المقابلات والملاحظات أعلاه ، تمكن للباحثة أن

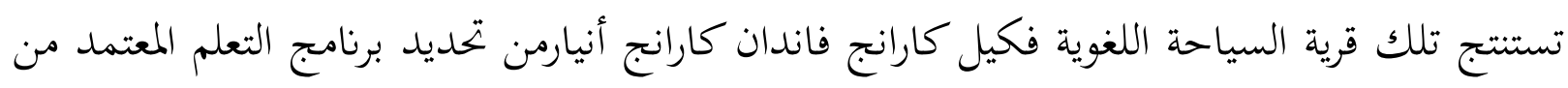
معهد عالي الرّاية سوكابومي.نظرا من الكتاب الذي يستخدم كمصدر مرجعي في أنشطة عملية التعلم. وأما ترتيب مواد الدراسة عملية مادة تعليم اللغة العربية في قرية السياحة اللغوية فكيل كارانج

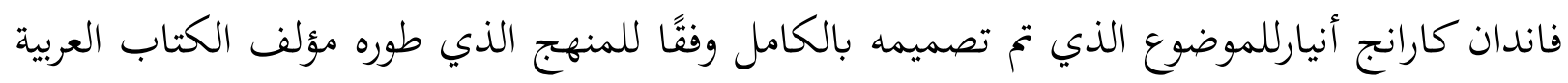

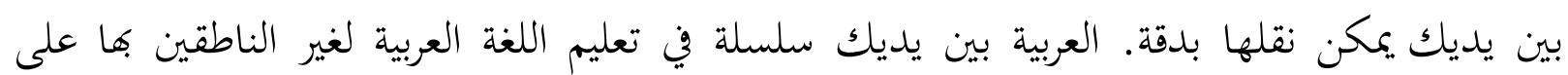
الأقل أعطت لوغا الخاص في عملية تطوير اللغة العربية في إندونيسيا. ومن الخصائص أن يجعل المتعلم قادرًا على إتقان ثلاث قدرات في وقت واحد ، وتشمل هذه القدرات المهارات اللغوية ومهارات الاتصال والقدرات الثقافية.

المهارات اللغوية هي مهارات لغوية تمكن تحقيقها من خلال تعلم اللغة العربية باستخدام العربية بين يديك. تتضمن قدرة اللغة نفسها القدرة على السمع والقدرة على الكلام والقدرة على القراءة

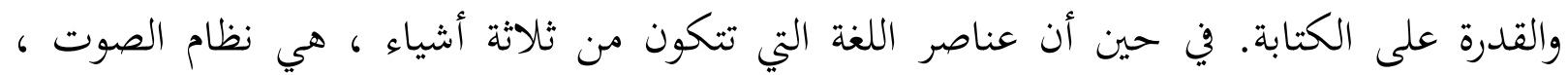
والمفردات ، وصياغة اللغة (مصحوبة بمعلومات حول قواعد النحو ، صرف ، وإملأ).

كتاب العربية بين يديك ليس فقط موجهًا إلى معرفة اللغة العربية، ولكن تم تطويرها أيضًا بحيث يكون الطلاب ماهرين في ممارسة المعرفة باللغة العربية. بحب ترقية المهارات اللغوية إلى مهارات

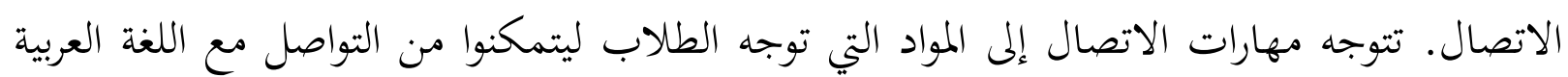
والتفاعل اللفظي والكتابي ، وأن يكونوا قادرين على ترتيب الجمل والتعبيرات باستخدام اللغة العربية. بامتلاك قدرتين ، وهما مهارات اللغة والاتصال ، يمكن الطلاب لتطوير هاتين قدرتين في

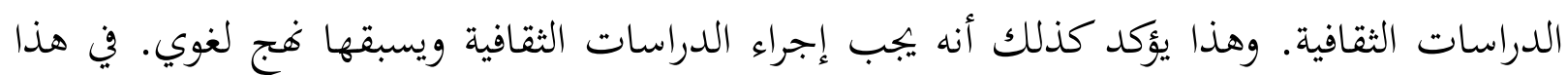

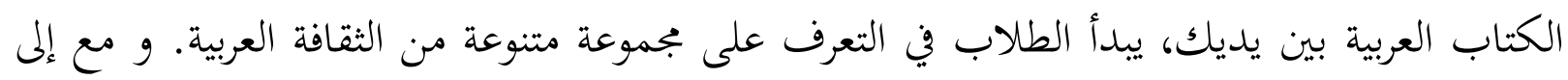

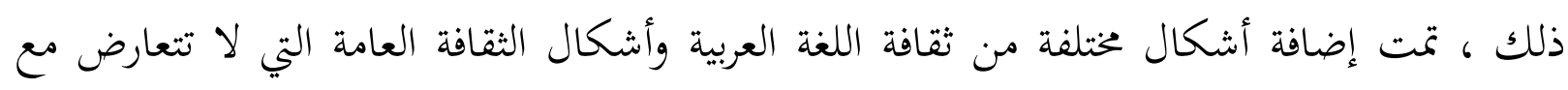

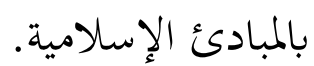


أما المواد المساندة من مصادر مختلفة سواء من الكتب العربية (مثل: النّحو الواضح، ملخص

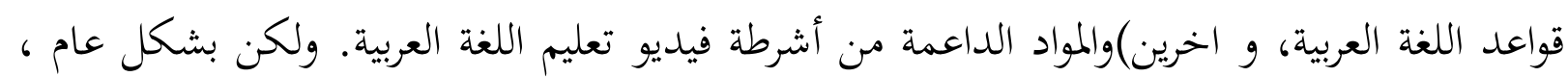

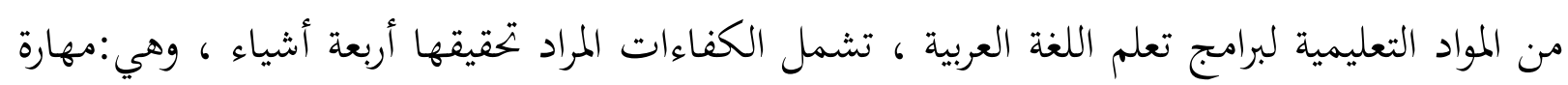
القراءة، مهارة الكلام، مهارة الإستماع و مهارة الكتابة.

ومن وسائل التعلم المستخدمة من قبل المعلمين ، وخاصة في برامج تعلم اللغة العربية بقرية

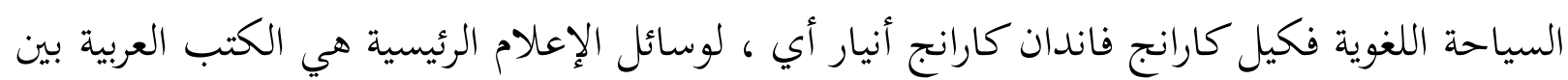

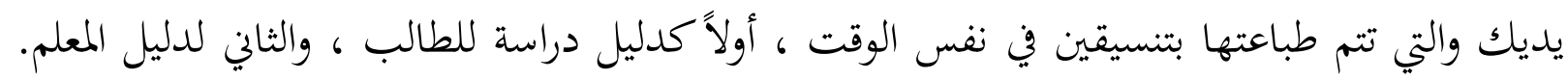

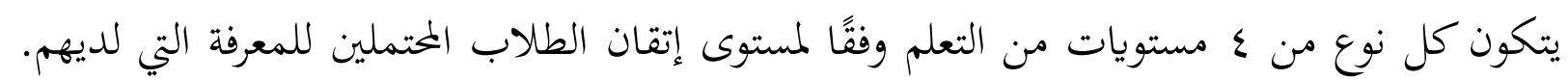

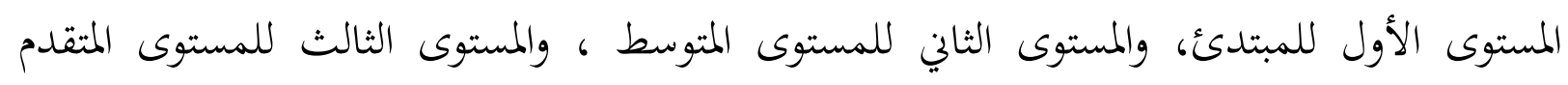
والمستوى الرابع للمستوى المتمايز.

في حين أن الوسائط الأخرى مثل السبورات وأجهزة الكمبيوتر المحمولة وأجهزة العرض

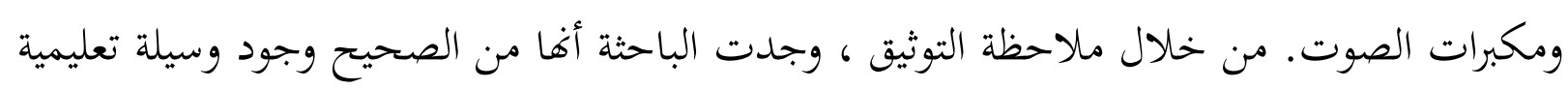

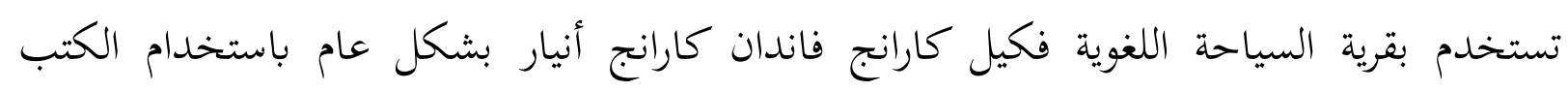
والسبورات كمصدر للتعلم.

وتطورت دراسات تعليم اللغة العربية المرتفعة ، وقد ولدت العديد من الكتب وأنساب تعليم

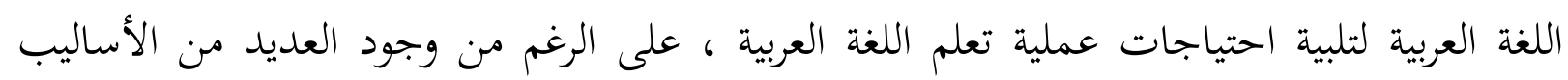

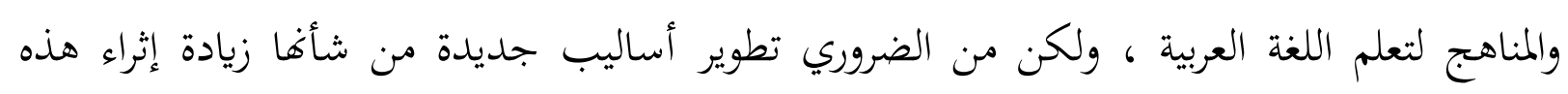
الدراسة . كتاب واحد يعرض الأساليب وتعلم اللغة العربية هو العربية بين يديك.

العربية بين يديك مصممة وموجهة لتعليم الكبار ، سواء من خلال التعلم من خلال المؤسسات التعليمية الرسمية وغير الرسمية والتعلم المستقل. يمكن القيام به الثلاثة باستخدام كتاب العربية بين يديك. بلديك. استخدم كتاب العربية بين يديك استخدموا أساليب التعلم الحديثة وكذلك أساليب التعلم

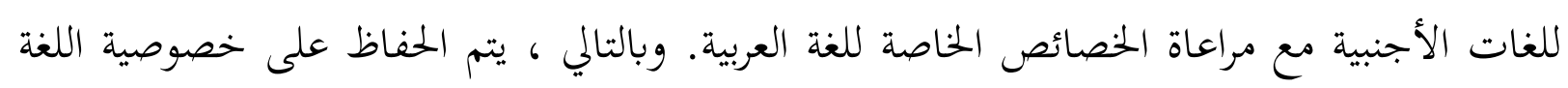
العربية على الرغم من تكييفها في طرق العرض الحديثة. 
تعليم اللغة العربية بقرية السياحة اللغوية فكيل كارانج فاندان كارانج أنيار للبرامج المكثفة التي تغطي المواد الواردة في كتاب العربية بين يديك تختلف مناهج وأساليب التعلم المطبقة. بالنسبة للمواد

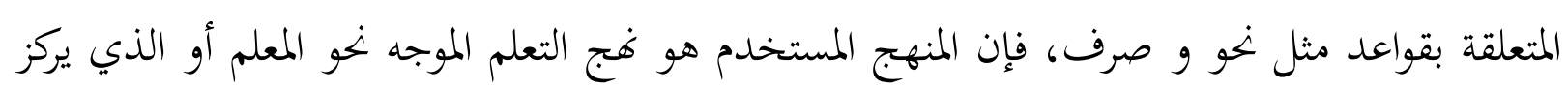

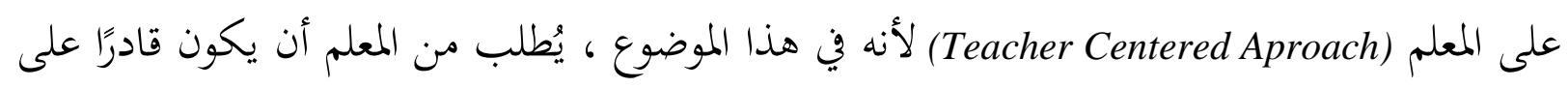

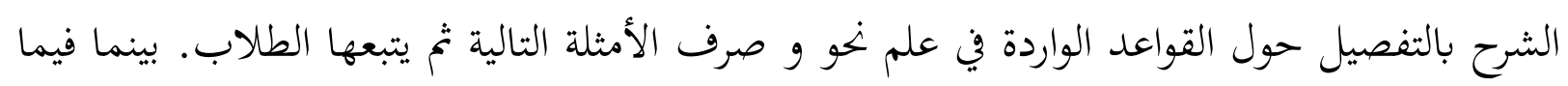
يتعلق بموضوع المحادثة والقراءة والكتابة والمفردات ، فإن نموذج النهج المستخدم هو فورئ فئج التعلم المتمحور

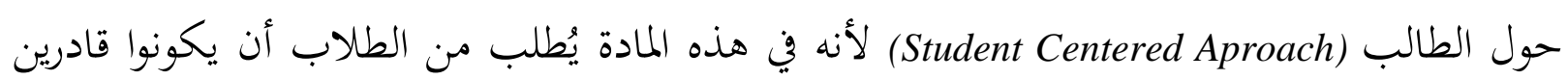
على الفهم مهارة القراءة، مهارة الكلام، مهارة الإستماع و مهارة الكتابة.

من خلال طريقة مراقبة التوثيق ، وجدت الباحثة أن هناك مراقبة طريقة وطريقة تعلم اللغة

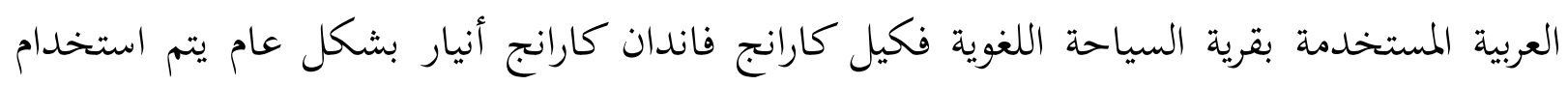
فجين: التعلم المتمحور حول المعلم ونماذج التعلم المتمحورة حول الطالب.

\section{تنظيم برامج تعليم اللغة العربية}

بشكل عام ، جميع المعلمين تقريبًا الذين يقومون بالتدريس في برامج تعليم اللغة العربية بقرية

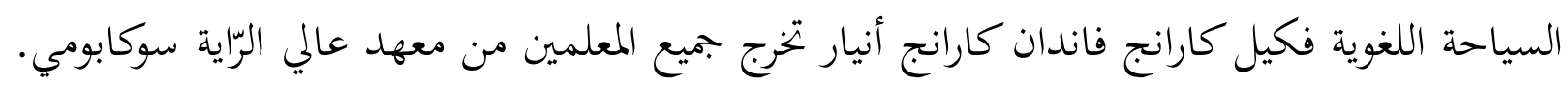

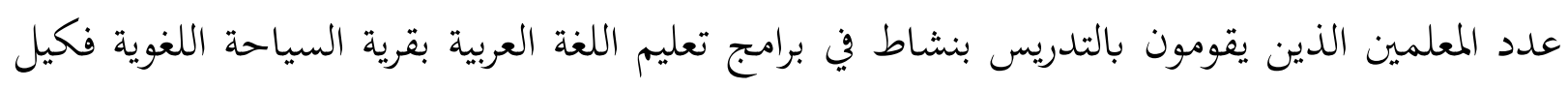

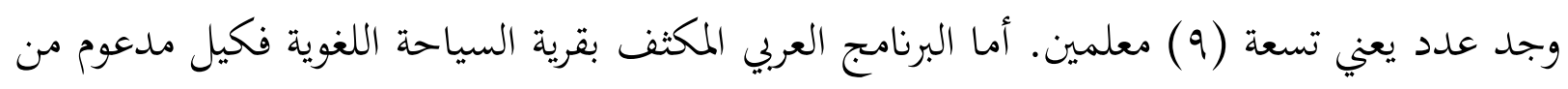

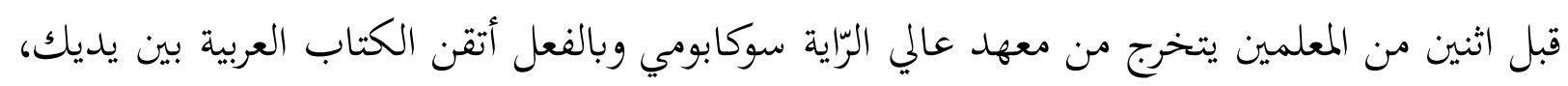
وواحد (1) مشرف للصعود. بينما تم أخذ المشرف من خريجي البرنامج المكثف للعام السابق.

تتمثل إحدى وظائف التقييم في برنامج التعلم في التحقق من الملاءمة بين أهداف البرنامج التي

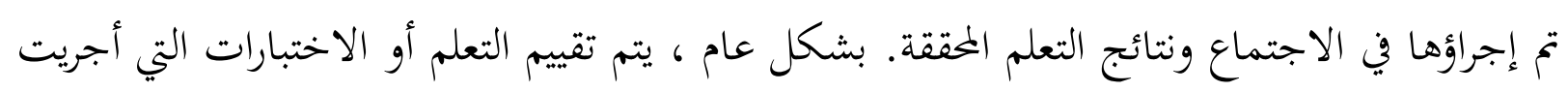

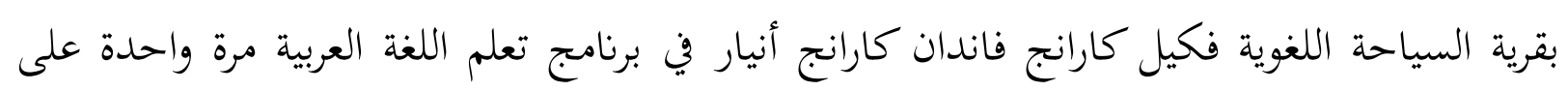


الأقل كل أسبوعين (r) ، من خلال جمع المعلمين. ثم يقوم كل معلم بالإبلاغ عن مدى تقدم التدريس

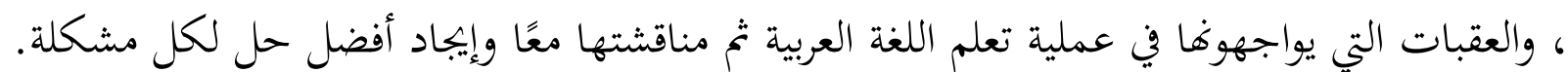
الوقت القياسي لتقديم جميع الدروس في الكتاب العربية بين يديك أكثر أو أقل من . .

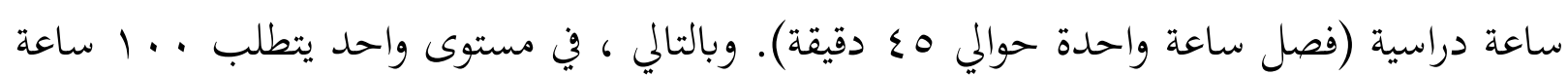

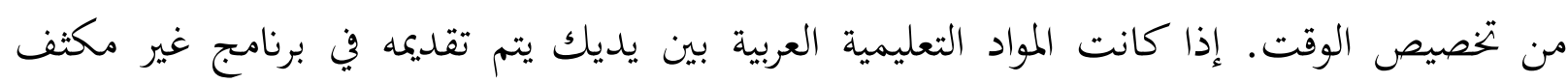

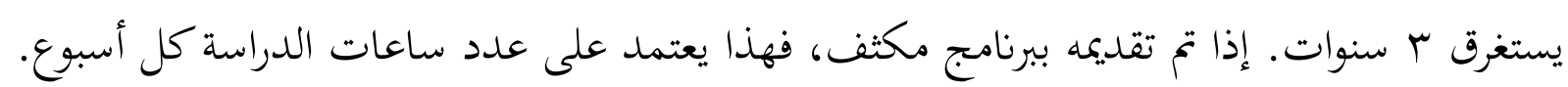
ثم للحصول على الحد الأدلى من مستوى الإنجاز هو ب \% م مع KKM من .7 من أصل

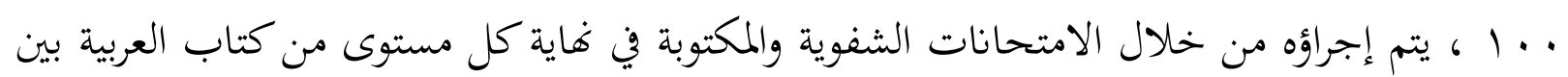

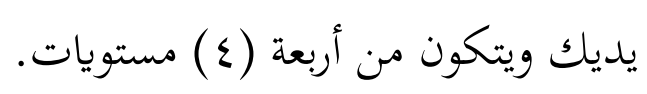

\section{تنفيذ برنامج تعليم اللغة العربية}

تنفيذ برنامج تعلم اللغة العربية بقرية السياحة اللغوية فكيل كارانج فاندان كارانج أنيار بما فيها:

$$
\text { الأنشطة الأولية }
$$

قبل دخول الفصل ، أعد المعلم المواد والوسائط التي سيتم استخدامها للتدريس. ثم يبدأ المعلم في

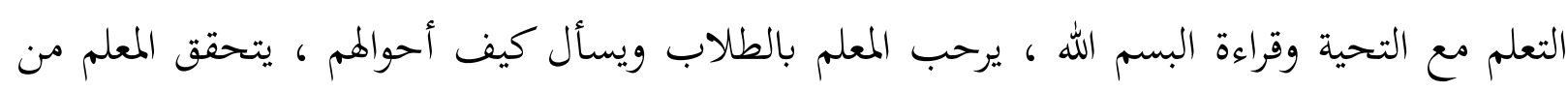

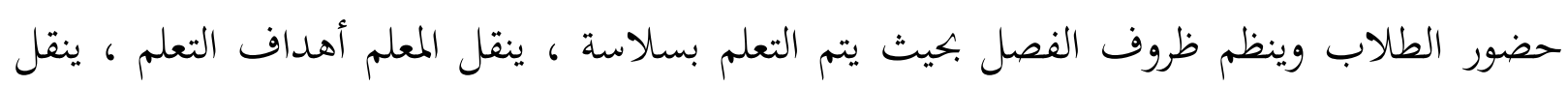
المعلم موضوع / عنوان المادة التعليمية التي سيتم مناقشتها. ب) الأنشطة الأساسية

يكرر الطلاب والمدرسون بعض المواد التي تمت دراستها سابقًا عن طريق سؤال عدد من الطلاب ، ثم يقوم المعلم بإرسال المادة باستخدام وسائط التعلم ، ويولي الطلاب اهتمامًا كبيرًا لتسليم

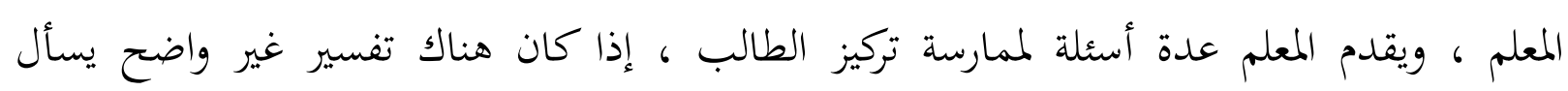

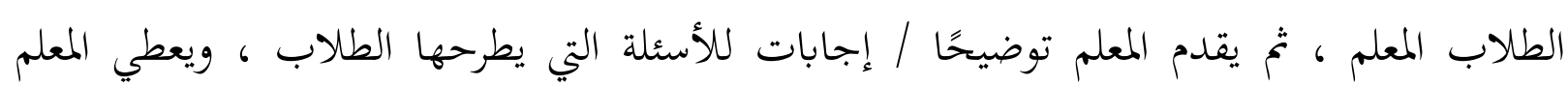
استنتاجات من المواد التعليمية. 
يقدم المعلم بعض الأسئلة للطلاب ، للتحقق من مستوى فهم الطالب ، يقدم المعلم دائمًا الدافع في تعلم اللغة العربية ، ويغلق المعلم التعلم ويقول حمد الله مع الطلاب. رقابة برنامج تعليم اللغة العربية

رقابة (controlling) هو نشاط يتم إجراؤه للإشراف وقياس ومقارنة الأنشطة التي نفذها المنظمة

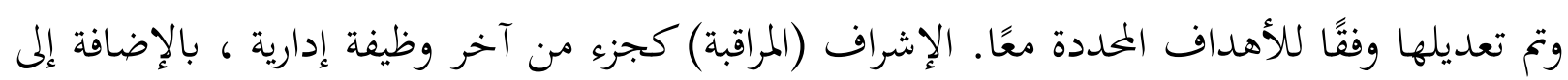

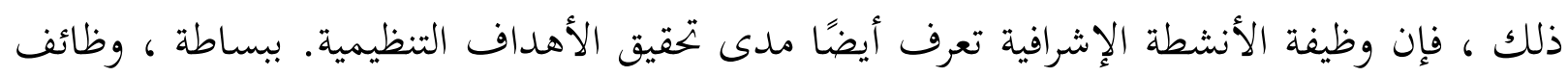

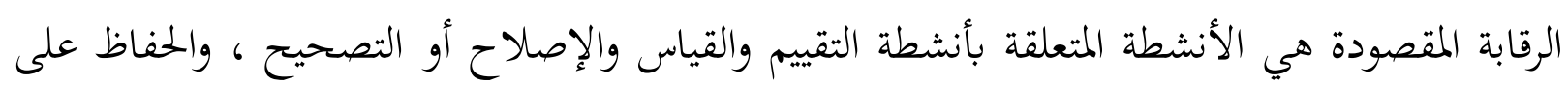

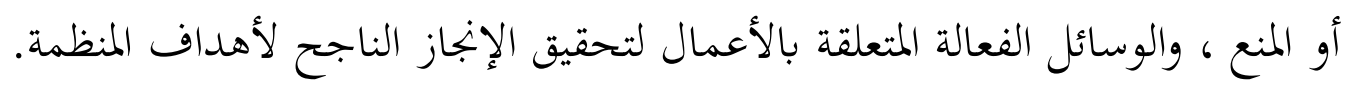

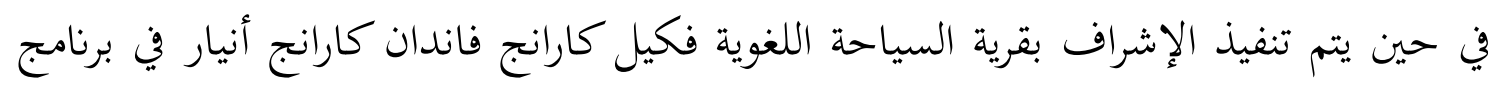

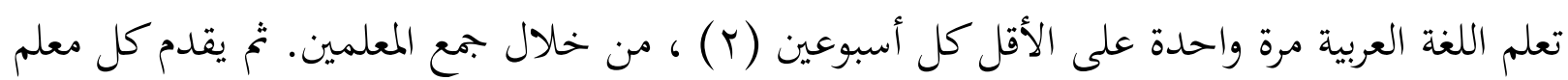
تقريرًا عن تقدم تدريسه ، وكذلك العوائق التي يواجهوها في عملية تعلم اللغة العربية لاحقًا ليتم مناقشتها معًا وإيجاد أفضل حل لكل مشكلة.

الخاتمة

بناء على أساس البحث السابقة و تحليلات على المعلومات والملاحظات أن برنامج تعليم اللغة العربية بقرية السياحة اللغوية فاكيل كارانج فاندان كارانج أنيار، يستطيع هذا البحث إلى إلى النتيجة هي

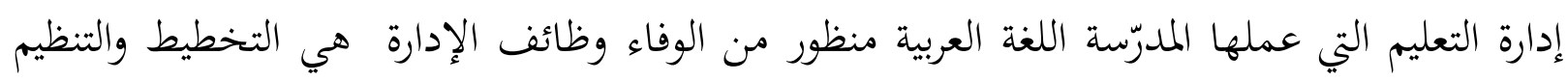
والتنفيذ والرقابة.

فتخطيط التعليم في هذه الحالة أهداف تعليم اللغة العربية بقرية السياحة اللغوية فكيل كارانج فاندان كارانج أنيار. يتم تنفيذ المنهج بقرية السياحة اللغوية فكيل كارانج فاندان كارانج أنيار يستخدم

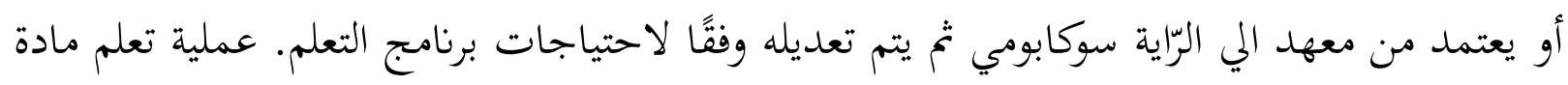

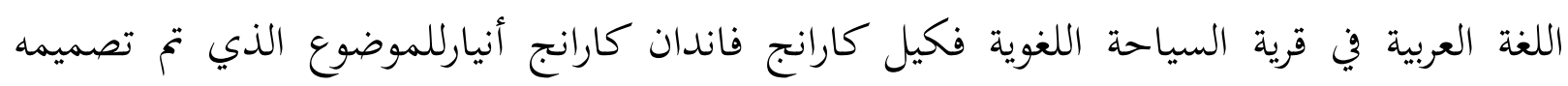
بالكامل وفقًا للمنهج الذي طوره مؤلف الكتاب العربية بين يديك يمكن نقلها بدقة. 

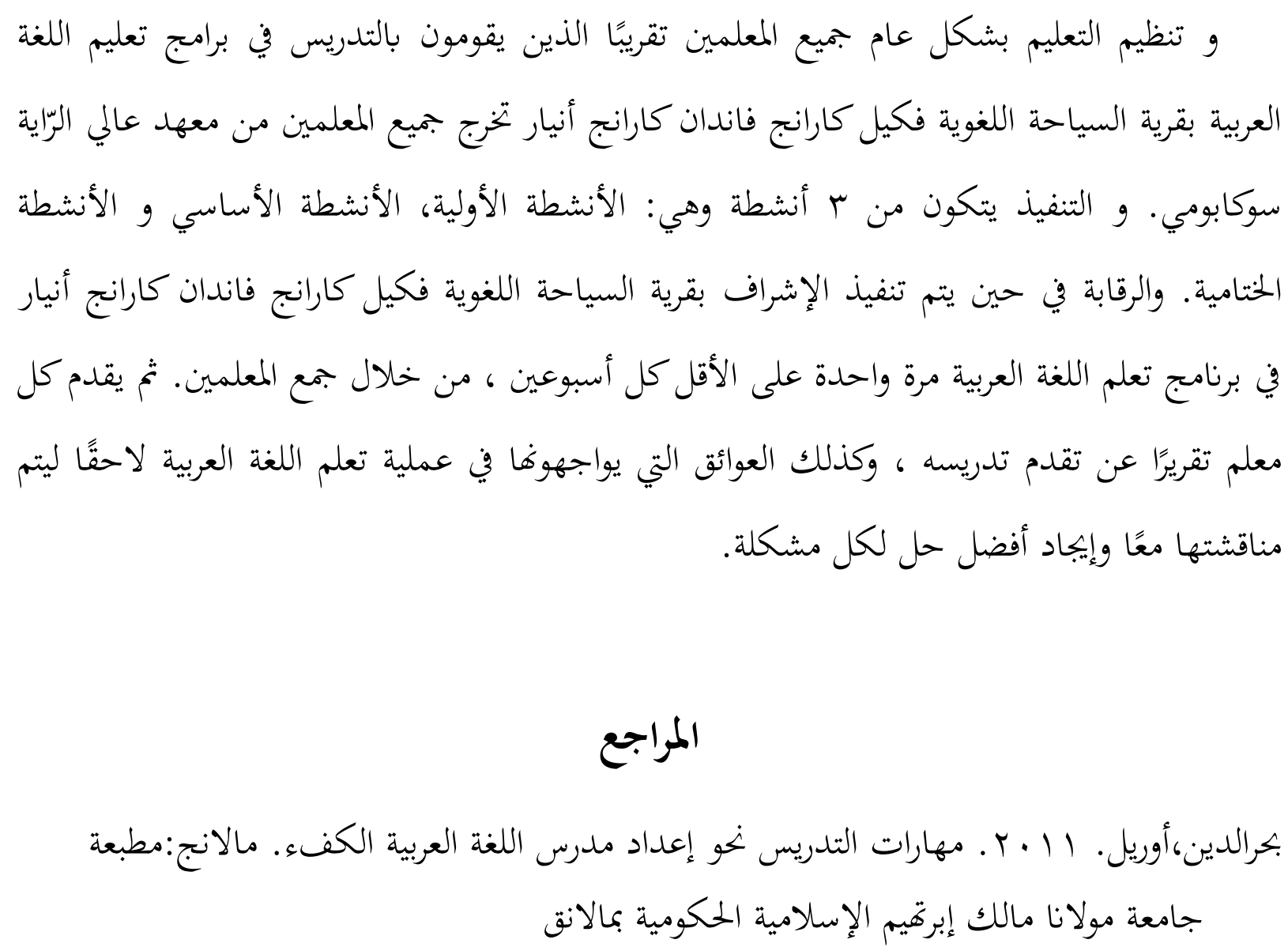

Abdul Majid. (2007). Perencanaan Pembelajaran. Bandung: PT. Remaja Rosdakarya.

Anshor, Ahmad Muhtadi. 2009. Pengajaran Bahasa Arab Media dan Metode-Metodenya. Yogyakarta. Teras.

Arifin, M. 2000. Filsafat Pendidikan Islam. Jakarta: Bumi Aksara

Creswell, John W. Research Design Pendekatan Kualitatif, Kuantitatif dan Mixed. Terjemahan oleh Achmad Fawaid. 2012. Yogyakarta: Pustaka Pelajar

Emzir. 2012. Metodologi Penelitian Kualitatif: Analilis Data. Jakarta: PT. Raja Grafindo Marzuki, Saleh. H.M. (2010). Pendidikan Nonformal. Dimensi dalam Keaksaraan Fungsional, Pelatihan, dan Andragogi. Bandung: Penerbit Rosda.

Muhaimin. 2009. Manajemen pendidikan: Aplikasi dalam Penyusunan Rencana Pengembangan Sekolah/Madrasah. Jakarta:Prenadamedia Group.

Omar Hamalik, 2007. Maanjemen Pengembangan Kurikulum,Bandung: PT Rosda Karya

Patilima, Hamid. 2011. Metode Penelitian Kualitatif. Bandung: Alfabeta

Prastowo, Andi. 2016. Memahami Metode-metode Penelitian: Suatu Tinjauan Teoritis dan Praksis. Yogyakarta: Ar-ruzz Media

Rifa, M. 2019. Manajemen Organisasi Pendidikan. In Journal of Chemical Information and 
ATHLA : Journal of Arabic Teaching, Linguistic And Literature, 1, (2), 2020

Modeling (Vol. 53). https://doi.org/10.1017/CBO9781107415324.004

Sagala, Syaiful. 2013. Konsep dan Makna Pembelajaran. Bandung: Alvabeta

Sugiyono. 2010. Memahami Penelitian Kualitatif. Bandung: Alfabeta

Undang-Undang RI No. 20 Tahun 2003 Tentang Sistem Pendidikan Nasional.

Usman, Husaini \& Akbar, Purnomo Setiadi. 2009. Metodologi Penelitian Sosial. Jakarta: PT Bumi Aksara 